\title{
A (RE) CONSTRUÇÃO DOS CONCEITOS DE NATUREZA, MEIO AMBIENTE E EDUCAÇÃO AMBIENTAL POR PROFESSORES DE DUAS ESCOLAS PÚBLICAS*
}

\author{
(Re) construction of the concepts of environment, \\ nature and environmental education \\ with teachers from two public schools
}

Aguinel Messias de Lima ${ }^{1}$

Haydée Torres de Oliveira ${ }^{2}$

\begin{abstract}
Resumo: Esta pesquisa foi realizada com professores de duas escolas públicas com o objetivo de (re) construir conceitos de natureza, meio ambiente e Educação Ambiental (EA). Na primeira etapa de coleta de dados, foi utilizado um formulário com questões abertas aplicadas a 23 professores da Escola Estadual de Ensino Médio e a sete professores da Escola Municipal de Ensino Fundamental. $\mathrm{Na}$ segunda etapa, foi realizada uma "oficina conceitual" em cada escola. Os professores da Escola de Ensino Médio possuem formação acadêmica diversa, e os da escola de Ensino Fundamental são formados em Pedagogia. As análises dos resultados apontaram, em ambas escolas, uma mudança conceitual de EA preservacionista/recursista para transformadora; de meio ambiente como biosfera para o multidimensional; de natureza naturalista para uma perspectiva socioambiental. Por meio deste estudo, propõe-se discutir uma proposta de EA a partir da (re) construção de saberes com a coletividade de professores.
\end{abstract}

Palavras-chave: Natureza. Meio ambiente. Educação escolar. (Re) construção de conceitos.

Abstract: This research was accomplished with teachers from two public schools with aim of (re) building concepts of environment, nature and environmental education. At the first stage of data collection, a form with open questions was used, answered by 23 teachers from the State High School and seven teachers from the Municipal Elementary School. At the second stage, a "conceptual workshop" was used in each school. The teachers from the State School have diverse academic backgrounds and the ones from the Municipal school had graduated in Pedagogy and History. The analysis of the results for both schools showed a conceptual change from a preservationist/resourcing of Environmental Education to a transforming one, from environment as biosphere to multidimensional; from naturalist nature to a socio-environmental perspective. Through this study a proposal for Environmental Education starting from the (re) construction of groups of teachers can be discussed.

Keywords: Nature. Environment. School education. (Re)construction of concepts.

\footnotetext{
* Apoio: Fundação de Amparo a Pesquisa de Mato Grosso,Universidade do Estado de Mato Grosso (FAPEMAT/UNEMAT).

${ }^{1}$ Graduado em Ciências Biológicas, doutor em Ecologia e Recursos Naturais. Professor, Escola Estadual

"Onze de Março". Cáceres, MT, Brasil. <aguinelm@top.com.br>

${ }^{2}$ Graduada em Ciências Biológicas. Docente, Departamento de Hidrobiologia e Programa de Pós-Graduação em Ecologia e Recursos Naturais, Universidade Federal de São Carlos, SP, Brasil. <haydee@ufscar.br>
}

${ }^{1}$ Rua dos Martins Willins, $\mathrm{n}^{\circ} 73$

Bairro Cavalhada I - Cáceres, MT

$78.200-000$ 


\section{Buscando compreender os conceitos de natureza, meio ambiente e Educação Ambiental}

Nas últimas décadas, a histórica mudança socioambiental, bem como a necessidade do desenvolvimento de ações educativas, requer uma constante revisão dos conceitos de natureza, meio ambiente e Educação Ambiental (EA). Assim, urge a necessidade da (des)construção de conceitos que são apropriados pelos atores sociais, sob a influência da atual ideologia hegemônica. Neste estudo, foi necessário discutir e refletir sobre esses conceitos preestabelecidos, para que pudéssemos ampliar as perspectivas de modo a incorporarmos a visão socioambiental da abordagem conceitual. Dessa forma, podemos ter um pouco mais de clareza sobre essas concepções, a fim de delinearmos nossas discussões em torno dos conceitos relevantes para ação em EA. Para Tamaio (2002, p. 37), a nossa "prática de elaboração conceitual é política e, ao mediatizarmos a construção dos conceitos-chave na temática ambiental, devemos fazê-lo sob uma perspectiva de ressignificação do contexto histórico-cultural".

Para tratarmos da concepção de natureza, dialogamos com diferentes teóricos, como Tuan (1980), Gonçalves (2002), Tamaio (2002), Dulley (2004). A respeito de meio ambiente, dialogamos com Fernandes Neto (2004), Sauvé (2003, 2005), Oliveira (2006). E, sobre o conceito de EA, recorremos às discussões de Segura (2001), Layrargues (2002), Carvalho (2004a, 2004b), Guimarães (2005), Loureiro (2004). A partir desses teóricos, foi possível dar início à discussão a respeito da concepção do elemento constitutivo do ambiente e da EA.

Nesta pesquisa, objetivamos compreender a concepção dos professores sobre os conceitos mencionados, a fim de (re)construirmos tais conceitos, com a participação coletiva dos professores pesquisados, como elementos para formação básica de educadores ambientais. Para isso, foram utilizadas três questões, a saber: Para você, o que é natureza? O que é meio ambiente? O que é Educação Ambiental? A partir das concepções detectadas, foi possível refletir sobre propostas de formação em EA no âmbito das escolas pesquisadas.

Os aportes teóricos, a seguir, discutem as três concepções citadas anteriormente. Para Tuan (1980, p. 152), o termo Natureza relaciona-se com o que fora designado pelos gregos pré-socráticos de "physis", cujo significado é "Total ou Totalidade". Esse termo tem perdido o sentido no uso popular, dado a sua complexidade. Para o autor, a natureza, como selvagem, ainda traz uma ideia de lugar rústico, perigoso e feio. Essa ideia formada é tida como verdade no imaginário de muitas pessoas, sobretudo para aquelas que não tiveram experiência com o campo ou ambientes menos modificados culturalmente.

Historicamente, a ideia de uma natureza rústica tem trazido problemas na relação entre homem e natureza. Segundo Gonçalves (2002, p. 35), a partir da Revolução Industrial, teve-se a "ideia de uma natureza objetiva e exterior ao homem, o que pressupõe uma ideia de homem nãonatural e fora da natureza; esta cristaliza-se com a civilização industrial inaugurada pelo capitalismo". De acordo com Guimarães (2005), nas sociedades atuais, a humanidade assume, cada vez mais, a consciência do individual, deixando de se integrar à natureza como um todo. Assim, a individualização chega ao extremo, levando o homem a se afastar da natureza. Essa desintegração inviabiliza o homem de perceber as relações harmônicas ou o desequilíbrio da natureza.

Para Gonçalves (2002, p. 23), o conceito de "natureza não é natural", haja vista ser "criado e instituído pelo homem". Portanto, a concepção de Natureza é algo constituído e 
construído no âmbito social, histórico e espacial. Para o autor, a natureza se define, em nossa sociedade, por "aquilo que se opõe à cultura e esta é tomada como algo superior e que conseguiu controlar e dominar a natureza" (p. 26-27). Ou seja, é tudo aquilo que tem característica natural e que não apresenta intervenção antrópica. Dessa forma, a concepção de natureza tem mostrado uma relação de interesse social dos diversos grupos humanos.

Segundo Dulley (2004, p.17), a natureza, "entendida como mundo natural, pode diferir conceitualmente de ambiente e meio ambiente". O autor destaca que a "cultura que diferencia o homem dos demais animais, é civilizadora" e enfatiza que "o homem nasce num ambiente natural, mas, simultaneamente, num ambiente sociocultural" (p. 17). Art (apud DULLEY, 2004, p. 18) assevera que a "natureza é termo genérico que designa organismos e ambiente onde eles vivem: o mundo natural'. Para Lenoble (apud DULLEY, 2004, p. 19), "natureza não se resume ao físico, pois ela é antes de tudo um produto, um resultado da visão que o homem tem dela no tempo e espaço". Na perspectiva desses pesquisadores, a concepção de natureza é construída socialmente ao longo da história humana na Terra. Segundo Dulley (2004, p. 20), a "natureza e o ambiente seriam, portanto duas faces de uma mesmo moeda, sendo que o segundo teria conotação mais prática ou de utilidade, não só para o homem, mas também para qualquer espécie". De acordo com Carvalho (2003, p. 111), a natureza foi classificada segundo sua utilidade para as necessidades humanas, expressando, assim, pragmatismo antropocêntrico. Sendo assim, a terra cultivada era interpretada como boa e bonita, já, enquanto selvagem, era considerada ameaçadora e esteticamente desagradável.

Para Tamaio (2002, p. 37), a

[...] natureza é um conceito categorizado por seres humanos, portanto, fundamentalmente político, as suas concepções são variadas e estão intimamente relacionadas com o período histórico e a correlação de forças políticas das classes sociais determinadas historicamente.

Esse mesmo autor (TAMAIO, 2002) analisou e identificou seis concepções de natureza que foram construídas e partilhadas entre estudantes da escola pesquisada, a saber: romântica, visão dualista (homem x natureza), sempre "harmônica, enaltecida, maravilhosa, com equilíbrio e beleza estética, algo belo e ético" (p.43); utilitarista, também “dualística", interpretada como fornecedora de vida e de recursos ao homem (leitura antropocêntrica) (p. 44); científica, abordada como uma "máquina inteligente e infalível"; generalizante, forma muito ampla, vaga e abstrata: "tudo é natureza" (p. 45); naturalista, que se refere a tudo que não sofreu ação de transformação pelo homem (as matas, bichos, os alimentos, entre outros); socioambiental, desenvolve uma "abordagem histórico-cultural”, reintegrando o homem à natureza e, muitas vezes, o homem surge como responsável pela degradação ambiental (p.46). Foram constatados vários discursos e concepções de natureza. Portanto, um dos desafios dos educadores ambientais é interpretar e compreender a diversidade de categorias conceituais de natureza nos diferentes territórios pedagógicos.

As particularidades do termo meio ambiente levam a uma concepção muitas vezes difusa e variada desse vocábulo, o que acarreta uma incompreensão do verdadeiro sentido da Educação Ambiental transformadora. Dessa forma, os aportes teóricos colaboram para o diálogo e interpretação do que seja meio ambiente, tanto na comunidade científica como fora dela. 
De acordo com Dulley (2004, p. 20), o "ambiente seria, portanto, a natureza conhecida pelo sistema social humano (composto pelo meio ambiente humano e o meio ambiente das demais espécies conhecidas)". Para o autor (DULLEY, 2004), há uma diferença entre ambiente e meio ambiente: o primeiro refere-se a "todas as espécies", enquanto o segundo relacionase "sempre a cada espécie em particular". Especificamente no caso da espécie humana, "seu meio ambiente corresponderia à natureza conhecida, modificada em relação aos interesses do seu sistema produtivo" (DULLEY, 2004, p. 21). Nesse sentido, "a noção de ambiente pode ser considerada como resultado do pensamento e do conhecimento humanos e do seu trabalho intelectual e físico sobre a natureza, e corresponde, portanto, à natureza trabalhada" (DULLEY, 2004, p. 22). Para o autor, enfim, "o conjunto dos meios ambientes de todas as espécies conhecidas pelo homem constituiria o ambiente, ou seja, a natureza conhecida pelo homem" (DULLEY, 2004, p. 25).

Para Guimarães (2005, p. 12), o meio ambiente é uma “unidade que precisa ser compreendida inteira, e é através de um conhecimento interdisciplinar que poderemos assimilar plenamente o equilíbrio dinâmico do ambiente". Ressalto, porém, que seria muita pretensão pensar que a pratica interdisciplinar pudesse compreender a dinâmica do meio ambiente na sua plenitude. Mas, diante da complexidade ambiental, há necessidade de se utilizar o método da interdisciplinaridade, para estabelecer o diálogo de saberes e da relação simbiótica entre os diversos sujeitos envolvidos com sua análise, a fim de se tentar compreender a multidimensionalidade ambiental.

Diversos pesquisadores investigaram a concepção de atores sociais partindo do contexto sócio-histórico da relação humana com o ambiente. Nas pesquisas realizadas por Oliveira (2006), e de Fernandes, Cunha e Marçal Júnior (2003), foram identificadas quatro categorias que demonstram a concepção de meio ambiente, a saber: biológica, biológica-física, antropocêntrica e não elucidativa. No trabalho desenvolvido por Fernandes Neto (2004, p. 85), em que cita Tabanez (2000 apud FERNANDES NETO, 2004), foram identificadas quatro categorias: naturalista, globalizante, antropocêntrica e genérica. Sauvé identifica, por meio do discurso e da prática em EA, dez categorias para os diferentes tipos de concepção paradigmática sobre ambiente:

El medio ambiente puede entender-se como la naturaleza (que apreciar, que preservar), o puede ser abordado como recurso (que administrar, que compartir), o como problema (que prevenir, que resolver), o bien, como sistema (que comprender para tomar mejores decisiones), puede ser igualmente percibido como medio de vida (que conocer, que organizar), o bien como contexto (trama de elementos interrelacionados y de significación, que destacar), o como territorio (lugar de pertenencia y de identidade cultural), o como paisaje (que recorrer, que interpretar), puede también ser abordado como biosfera (donde vivir juntos y a largo plazo), o igualmente, como proyeto comunitário (donde comprometerse). (SAUVÉ, 2003, p. 4)

Para Carvalho (2004a, p. 16), quando se fala em EA, refere-se a um adjetivo "ambiental" aplicado a um substantivo "Educação". Isso tem proporcionado, nos diversos territórios, 
diálogos entre educadores, na tentativa de identificar e compreender o significado da EAe buscar a identidade dessa expressão.

Neste sentido, Layrargues (2002) destaca duas principais concepções de Educação Ambiental: a conservadora/tradicional e outra transformadora/crítica. A primeira prioriza uma educação pretensamente apolítica e mantenedora do status quo social, enquanto a segunda contribui para a transformação da realidade socioambiental. Para o autor, a

[...] prática pedagógica da EA tradicional volta-se ao ensino de ecologia, aproximando-se da educação conservacionista, enquanto que a prática pedagógica da Educação Ambiental crítica volta-se à reflexão do funcionamento dos sistemas sociais, além dos sistemas ecológicos.

(LAYRARGUES, 2002, p. 190)

A EA conservadora ou tradicional preocupa-se com as ações pautadas na transmissão de conhecimento e na mudança de comportamento em relação à conservação da natureza. A educação, baseada nesta concepção, considera, predominantemente, os aspectos naturais sem correlacioná-los aos aspectos sociais, culturais etc. Já a EA transformadora se preocupa com a mudança da realidade socioambiental e tem sido defendida por vários teóricos atuais da EA, tanto brasileira como de outros países. De acordo com Layrargues (2002, p. 191), "a EA crítica é um processo educativo eminentemente político, que visa ao desenvolvimento nos educandos de uma consciência crítica acerca das instituições, atores e fatores sociais geradores de riscos e respectivos conflitos socioambientais".

O trabalho de Sauvé (2005) apresenta 15 correntes de EA. Dentre elas, enfatizamos somente as correntes identificadas na presente pesquisa: corrente naturalista com enfoque educativo, centrada na relação com a natureza; conservacionista/recursista, centrada na "conservação" dos recursos ou na gestão ambiental; resolutiva, compreende o meio como um conjunto de problemas; científica, enfatiza o processo científico e a identificação das relações de causa e efeito; humanista, com ênfase na dimensão humana do MA (natureza/cultura); práxica, com destaque na aprendizagem durante ação, pela ação e para melhoria da ação; crítica social, analisa as dinâmicas sociais que se encontram na base das realidades e problemáticas ambientais.

\section{Procedimentos metodológicos}

Desenvolvemos uma pesquisa do tipo qualitativa, baseada nos pressupostos teóricometodológicos de Bogdan e Biklen (1994), André (1995) e na pesquisa participante (BRANDÃO, 2001).

A presente pesquisa foi realizada na Escola Estadual de Ensino Médio (EEEM) e na Escola Municipal de Ensino Fundamental (séries iniciais) - (EMEF), ambas localizadas no sudoeste de Mato Grosso. A escolha das duas escolas deu-se em razão de possuírem, em seus quadros, professores com formação acadêmica diversificada.

A escolha dos professores se deu de acordo com o interesse e disponibilidade em participar da pesquisa. Optou-se, pelo menos, por um participante de cada área do conheci- 
mento acadêmico, para que houvesse maior diversificação e complexidade de respostas entre estes participantes.

A coleta de dados aconteceu entre os meses de março e novembro de 2007. Para obter informações a respeito do perfil dos participantes e entender a concepção de natureza, meio ambiente e EA de cada professor, foram utilizados, na primeira etapa da coleta de dados, questionários estruturados (autorresposta) com perguntas abertas, que foram respondidas por 23 professores da escola de Ensino Médio e por sete da de Ensino Fundamental. Nessa etapa, os dados obtidos por meio das respostas individuais das diferentes concepções foram analisados, classificados e apresentados em categoria, conforme Tabelas 2 e 3.

Durante a segunda etapa da coleta de dados, utilizou-se a metodologia participativa, aplicada em uma oficina conceitual em duas escolas, com duração, em média, de quatro horas para cada encontro.

$\mathrm{Na}$ EEEM, a coleta de dados ocorreu durante três encontros, com três grupos de participantes: grupo 1 (G1), com seis professores (26,1\%); grupo 2 (G2), com 13 professores (56,5\%), e grupo 3 (G3), com quatro professores $(17,4 \%)$, totalizando 23 participantes. Nessa escola, dada a dificuldade e incompatibilidade em promover encontros com os 23 professores em um único horário, procedeu-se à divisão em três grupos distintos. Nesse sentido, a oficina aconteceu no coletivo, com a participação de professores dos três grupos menores em três períodos distintos (G1 no período matutino, às terças-feiras; G2, quintas-feiras/vespertino; e G3, quintas-feiras/noturno). Na EMEF, a oficina foi realizada com apenas um grupo (G4, quartas-feiras/vespertino), com sete (100\%) participantes.

Nessa segunda etapa, foram apresentados, aos quatro grupos (projetando-se numa tela), os diversos conceitos individuais (resultantes da aplicação dos questionários na primeira etapa). Em seguida, procedeu-se à discussão, às leituras do texto e às reflexões para (re)construção do conceito, de forma interativa, coletiva e consensual do grupo. Durante a realização da oficina, foram realizadas leitura e discussão de um fragmento de um capítulo do trabalho de Gonçalves (2002) sobre a concepção de natureza; de Guimarães (2005), que trata do que é EA; de Tonissi (2005), que discute a educação dialógica, contextualizada, política e emancipatória. Em seguida, procedeu-se à discussão, às leituras e às reflexões para (re)construção do conceito no coletivo, em consenso no grupo. Nesse momento, o papel do pesquisador foi o de "mediador no processo da elaboração conceitual" (TAMAIO, 2002, p. 40), baseado em interações dialógicas e intencionais.

\section{Perfil dos professores participantes da pesquisa}

A Tabela 1 apresenta o perfil dos professores das duas escolas pesquisadas.

Os participantes da EEEM possuem entre vinte e sessenta anos, e os docentes da EMEF, trinta a 45 anos. Com relação a tempo de profissão, os professores da EEEM atuam como docentes há mais tempo que os professores da EMEF. A maioria dos professores da EMEF é natural da cidade onde ocorreu a pesquisa. Na escola EEEM, detectamos que uma minoria é oriunda da cidade onde desenvolvemos este estudo. Dos professores investigados, a maior parte é do sexo feminino. Os participantes da EEEM possuem formação acadêmica nas diversas licenciaturas, e dois fizeram curso de bacharelado: um em Agronomia e outro em Direito. Enquanto, na EMEF, a maioria é pedagogo, somente um é licenciado em História. 
A (re) construção dos conceitos ...

Tabela 1. Perfil dos professores participantes da pesquisa nas duas escolas (EEEM/EMEF).

\begin{tabular}{|c|c|c|}
\hline Perfil & EEEM & EMEF \\
\hline Sexo & 78,3 \% Feminino e 21,7 \% Masculino. & $100 \%$ feminino. \\
\hline Idade & 20 a 60 anos. & 30 a 45 anos. \\
\hline Tempo de profissão & 01 a 30 anos. & 01 a 25 anos \\
\hline Naturalidade & $\begin{array}{l}21,7 \% \text { de Cáceres e } 78,3 \% \text { de outras } \\
\text { localidades. }\end{array}$ & $\begin{array}{l}85,7 \% \text { de Cáceres e } 14,3 \% \\
\text { de outra localidade. }\end{array}$ \\
\hline Área de formação acadêmica & $\begin{array}{l}\text { 21,8 \% Geografia; 21,8 \% História; } 17,5 \% \text { Letras; } \\
\text { 17,4\% Biologia; 4,3\% Física; 4,3\% Matemática; } \\
\text { 4,3\% Educação Física; 4,3 \% Estudos Sociais/ } \\
\text { Pedagogia/bacharelado em Direito; 4,3\% Química/ } \\
\text { Biologia/bacharelado em Agronomia. }\end{array}$ & $\begin{array}{l}85,7 \text { \% licenciados em } \\
\text { Pedagogia, } 14,3 \% \text { em } \\
\text { História. }\end{array}$ \\
\hline Área de atuação & $\begin{array}{l}\text { Todos atuam na mesma área de formação, exceto } \\
02 \text { professores licenciados em Biologia, que } \\
\text { lecionam Química. }\end{array}$ & $\begin{array}{l}\text { Atuam em todas as } \\
\text { disciplinas das séries iniciais } \\
\text { do Ensino Fundamental. }\end{array}$ \\
\hline
\end{tabular}

Inferimos, desses dados, que a formação da docência está relacionada à oferta do ensino nas escolas pesquisadas. A maior parte dos professores participantes da pesquisa na EEEM possui formação acadêmica em licenciatura plena nas áreas das Ciências Humanas, Sociais, Naturais e Exatas. Enquanto, na EMEF, são licenciados nas áreas de Humanas e Sociais.

\section{Natureza, meio ambiente e Educação Ambiental: concepção individual dos professores}

A análise da categoria natureza, realizada na primeira etapa da pesquisa, foi baseada em Tamaio (2002), e as análises das categorias de meio ambiente e EA foram baseadas nas concepções de Sauvé $(2003,2005)$. Na EEEM, foram identificadas cinco categorias de natureza e de meio ambiente, quatro de EA (Tabela 2).

De acordo com os resultados dos questionários aplicados aos professores da EEEM, $47,9 \%$ demonstraram a tendência da concepção de natureza naturalista. Para esses professores, a natureza é um espaço natural (ecossistema) com predominância dos aspectos bióticos

Tabela 2. Concepções de Natureza, meio ambiente e Educação Ambiental dos professores da EEEM.

\begin{tabular}{|c|c|c|c|c|c|}
\hline Categoria & $\begin{array}{c}\text { Natureza } \\
\%\end{array}$ & Categoria & $\begin{array}{c}\text { Meio } \\
\text { Ambiente } \\
\%\end{array}$ & Categoria & $\begin{array}{c}\text { Educação } \\
\text { Ambiental } \\
\%\end{array}$ \\
\hline Naturalista & 47,9 & Sistema & 39,1 & Conservacionista/recursista & 74 \\
\hline Utilitarista & 17,4 & Lugar para viver & 34,9 & Humanista & 17,4 \\
\hline Generalista & 17,4 & Biosfera & 13,1 & Naturalista & 4,3 \\
\hline Socioambiental & 8,7 & Natureza & 4,3 & Científica & 4,3 \\
\hline Sagrada & 4,3 & Recurso & 4,3 & - & - \\
\hline Não elucidado & 4,3 & Não elucidado & 4,3 & - & - \\
\hline- & 100 & - & 100 & Total & 100 \\
\hline
\end{tabular}


(fauna/flora) e abióticos (água, rio, solo, atmosfera). As respostas de dois professores confirmam essa tendência: "o espaço natural do globo terrestre, caracterizado pelo verde das matas e pelas águas do rio"; "é o ecossistema formado por seres vivos, plantas, rios, mares, animais, etc". As respostas demonstraram que a natureza está relacionada com o espaço e o sistema ecológico natural composto por "bichos" (animais) e "matas", similar ao que Tamaio (2002, p. 46) identificou em sua pesquisa.

Quanto à concepção de natureza, 17,4\% dos professores entrevistados apresentaram uma visão utilitarista de natureza. Nessa tendência, a natureza é vista como fonte de recurso para ser usufruído pela espécie humana, e sua sobrevivência está na dependência desta natureza, conforme a resposta de um dos professores: “[...] dela dependemos e temos obrigação de preservá-la o que ainda temos". Depreende-se que essas respostas destacam a tendência de uma natureza utilitarista numa visão "antropocêntrica e fornecedora de vida" para o ser humano, de acordo com Tamaio (2002, p. 44) e Carvalho (2004b).

Para 17,4\% dos professores investigados, o conceito de natureza é generalista, conforme descreveram dois deles: "tudo o que nos cerca"; "tudo ao nosso redor e está presente no meio ambiente". Todavia, esses professores não mencionaram o que seja esse "tudo" ao redor.

Dentre $8,7 \%$ das respostas, detectamos uma concepção de natureza com tendência socioambiental, conforme definição de Tamaio (2002, p. 44) e Carvalho (2004b, p. 36). Nessas respostas, emergiu a dimensão social (ser humano) e a sua relação com os aspectos biológicos e abióticos, como se pode constatar no trecho: "É o conjunto das relações animais, flora e homem (ser social) correlacionando com os fatores abióticos e/ ou não". Nessa resposta, pode-se observar a interação humana e dimensão ecológica como formas de reintegrar o ser humano à natureza. Somente $4,3 \%$ dos professores apresentaram a concepção de natureza como sagrada. Para esses participantes, ela é dádiva que Deus nos presenteou, um espaço sagrado e abençoado. Somente $4,3 \%$ não elucidaram uma concepção de natureza.

Com relação a meio ambiente, $39,1 \%$ dos professores conceberam meio ambiente como sistema (SAUVÉ, 2003), com ênfase no ecológico, relacionado aos aspectos natural, social e político, conforme as respostas de dois professores: "o conjunto que engloba o espaço, rios, lagos, a flora, a fauna, seja em uma floresta, mata, ou na cidade, vilarejos, o meio ambiente é lugar em que vivemos"; "tudo aquilo que nos circunda, é vida e a relação entre ela, o natural, social e político". Esta resposta destacou a multidimensionalidade (dimensão natural, social, político) do ambiente (MORIN, 2003; LEFF, 2003, 2006).

Com relação ao meio ambiente como um lugar para viver (SAUVÉ, 2003), 34,9\% dos professores consideraram-no como meio ou lugar onde vivemos ou moramos, como nossa casa, como o campo ou a cidade. Esses professores descreveram essa categoria como sendo o "habitat específico do ser humano", categoria também identificada por Dulley (2004). Segundo as falas de dois professores, meio ambiente "é o lugar onde vivemos, nosso hábital"; "É o meio em que vivemos [...]". Nessas falas, observa-se a predominância de uma concepção antropocêntrica, conforme discutido no trabalho de Oliveira (2006); Guimarães (2005), Fernandes, Cunha e Marçal Júnior (2003), entre outros autores.

Com relação ao meio ambiente como biosfera (SAUVÉ, 2003), 13,1\% dos professores consideram-no como espaço onde ocorre a interação entre os conjuntos de organismos vivos presentes no planeta Terra, conforme descrito na resposta de um professor: "o espaço de convivência dos seres do planeta Terra". O meio ambiente foi considerado, pelos participantes da 
pesquisa, como a interação e convivência dos organismos entre si num determinado espaço do planeta Terra.

$\mathrm{Na}$ descrição de meio ambiente como natureza, 4,3\% dos professores acreditam que é um local onde se encontram elementos naturais. Ou seja, um ambiente "puro e original", conforme define Sauvé (2003), é observado na resposta de um professor: "um local natural". Sendo assim, a natureza deve ser um local para ser preservado, admirado, mantendo-se o mais legítimo possível no seu estado natural.

Parte dos professores $(4,3 \%)$ descreveu meio ambiente como recurso quando revelaram a preocupação com os nossos recursos naturais. Essa ideia aponta para a preocupação com a esgotabilidade dos recursos naturais que estão à disposição do ser humano. De acordo com essa compreensão, a gestão dos recursos é fundamental para que se garantam as riquezas naturais, não somente para a humanidade, mas para a qualidade de vida planetária. Por último, $4,3 \%$ das respostas não detalharam essa concepção.

Os participantes manifestaram uma concepção de EA conservacionista/recursista (SAUVÉ, 2005), somando um porcentual de $74 \%$. As respostas apontam para uma "educação racional" que busca a transmissão de conhecimento dos aspectos constitutivos de ambiente (fauna/flora) com a finalidade da conservação do meio ambiente, bem como dos recursos naturais. Nessas respostas, depreendemos uma educação denominada de conservacionista, como revelem as respostas de dois professores que caracterizaram melhor esta tendência: " $a$ sensibilização da população para conservar o meio ambiente" e "conhecer os nossos potenciais naturais e o cuidado que devemos ter na utilização desses recursos etc".

A tendência humanista (SAUVÉ, 2005), detectada em 17,4\% das respostas, dá ênfase à dimensão humana na interface cultura e natureza, considera os valores humanos e o respeito interpessoal e a vida. Trata-se de uma EA para a convivência com o meio, o respeito à vida $\mathrm{e}$ às diferenças culturais, valorizando as mudanças atitudinais, como apontam trechos de respostas dos professores que caracterizam melhor essa tendência: "preparar o educando para o convivio no meio em que vive respeitando as diferenças culturais"; "educação para a vida, para a convivência; se respeitar para poder respeitar a vida". Conforme esses relatos, a referida tendência está voltada para a formação e preparação do ser humano e da sociedade para mudanças de atitude em relação ao ambiente social.

Uma pequena porcentagem das respostas (4,3\%) aponta para uma EA de tendência naturalista (SAUVÉ, 2005), quando menciona a importância da aprendizagem na interação humana para se viver de forma harmônica com a natureza: "aprender harmonizar com a natureza". Essa corrente está centrada na relação humana com o meio natural. Nesse caso, a natureza funciona como espaço educativo e meio de aprendizagem para o ser humano.

Um grupo menor de professores (4,3\%) aponta para uma EA que tem tendência científica (SAUVÉ, 2005). Nessa tendência, o enfoque é "cognitivo", e o meio ambiente é visto como objeto de conhecimento. Aqui está presente a ideia de se compreenderem conceitos científicos (sociais e ambientais) cuja finalidade é conscientizar as pessoas a respeito do ambiente, conforme afirma um professor: "Compreender os conceitos científicos e sociais no uso da consciência ambiental”. Ele apresenta, portanto, uma concepção de EA voltada para a aquisição de conhecimento sobre o ambiente.

A categoria apresentada na EEEM (Tabela 2) revela um paradigma de EA tradicional, conforme destaca Sauvé (2005). As categorias de EA, como "biosfera" e "sistema", destacam 
os aspectos biofísicos (natural e construído), sociais, políticos e o planeta Terra. As categorias "como lugar para viver", "como recurso" e de natureza "utilitarista", identificadas nas respostas dos professores, revelaram a visão antropocêntrica tanto na concepção de meio ambiente como na de natureza. Foi destacada a dimensão social tanta na concepção de meio ambiente "como sistema" e de natureza como "socioambiental". A concepção de meio ambiente "como natureza" é semelhante à de natureza "naturalista" e está relacionada com a dimensão natural no espaço ou lugar.

A seguir, foram identificadas, nas respostas dos questionários aplicados aos professores (primeira etapa) da EMEF, três tendências de meio ambiente e natureza e duas de EA (Tabela 3).

Tabela 3. Concepções de natureza, meio ambiente e Educação Ambiental dos professores da EMEF (I a V).

\begin{tabular}{|c|c|c|c|c|c|}
\hline Categoria & $\begin{array}{c}\text { Natureza } \\
\%\end{array}$ & Categoria & $\begin{array}{c}\text { Meio } \\
\text { Ambiente } \\
\%\end{array}$ & Categoria & $\begin{array}{c}\text { Educação } \\
\text { Ambiental } \\
\%\end{array}$ \\
\hline Naturalista & 71,4 & Lugar para viver & 57,1 & Preservacionista/recursista & 85,7 \\
\hline Utilitarista & 14,3 & Natureza & 28,6 & Resolutiva & 14,3 \\
\hline Meio ambiente & 14,3 & Sistema & 14,3 & - & \\
\hline- & 100 & - & 100 & Total \% & 100 \\
\hline
\end{tabular}

Em relação à concepção de natureza dos professores da EMEF (Tabela 3), 71,4\% descreveram a tendência naturalista proposta por Tamaio (2002). Nessa concepção está incluído o sistema com os "elementos naturais" (biofísicos): "plantas, animais, os rios, solo, ar puro etc", e os componentes essenciais da vida. Não depreendemos dessas respostas nenhuma menção à presença humana no sistema biofísico. Nessa concepção, percebe-se a relação dualística natureza $\mathrm{x}$ ser humano.

Para 14,3\% dos professores pesquisados, a concepção de natureza é utilitarista, como se pode constatar na seguinte resposta: "é tudo aquilo que a Terra nos oferece". Nesse sentido, a natureza é vista como fornecedora de recursos para nossa sobrevivência. Percebe-se uma visão também "antropocêntrica" de natureza, conforme definição de Gonçalves (2002), Tamaio, (2002) e Guimarães (2006). Em seguida, obtivemos 14,3\% das respostas que indicaram a concepção de natureza como praticamente sinônimo de meio ambiente, dado corroborado por Dulley (2004).

Entre 57,1\% das respostas obtidas, o meio ambiente é considerado lugar para se viver, conforme as respostas de dois professores: "o nosso local de vivência"; "tudo que nos rodeia e tudo que nos cercam”. Esta concepção destaca o meio ambiente como habitat específico para o ser humano, embora não detalhe o "tudo" que cerca o ser humano.

Em relação à concepção de meio ambiente, as respostas de $28,6 \%$ dos professores remetem a uma concepção natureza. Nesta, considera a dimensão natural, o espaço e os organismos biológicos inseridos no ambiente conforme observado na resposta de um professor: "lugar de muito verde, plantas, animais rio etc.". 
A (re) construção dos conceitos ...

Na concepção de 14,3\% dos professores, o meio ambiente é considerado como sistema, constituído de espaço natural onde vivemos (humanos) junto com outros organismos vivos (animais e vegetais), conforme observado nas respostas de um professor: "natureza, meio onde vivemos, onde vivem animais e vegetais". Nessa concepção, os professores descreveram a dimensão ecológico/natural e a social do ambiente.

Em relação à concepção de EA, as respostas de 85,7\% dos professores remetem a uma concepção conservacionista/recursista, conforme Sauvé (2005). Esta menciona EA como meio de conscientização para preservar a natureza. Esta tendência é revelada nas respostas, ao se referirem a uma EA para conservar o ambiente e manter os recursos naturais, conforme observamos em duas respostas dos professores: "conscientização para preservação da naturez̧a, uma educação voltada para o cuidado, o zelo, a proteção do meio ambiente"; [...] "mudança de comportamentos relacionados ao meio onde está inserido". Pode-se ainda observar a menção a uma EA "comportamentalista" (LAYRARGUES, 2002; CARVALHO, 2004b; TOZONI-REIS, 2004) em relação ao meio ambiente, conforme a resposta acima.

Em 14,3\% das respostas, a tendência EA como resolutiva aparece nas respostas que apontaram para uma educação capaz de promover mudança de atitude e tomada de decisão frente aos problemas ambientais. Nessa tendência, o meio ambiente é considerado como um conjunto de problemas e, também, como possibilidade de desenvolver habilidades voltadas para a busca de soluções para problemas ambientais, conforme destacou um professor: " $m u$ dança de atitudes, tomada de decisão frente aos problemas que mais interferem ao nosso redor".

$\mathrm{Na}$ EMEF, uma pequena percentagem revelou a concepção de natureza como sinônimo de meio ambiente (Tabela 3). Tanto na concepção de natureza "naturalista" como na de meio ambiente "como natureza" são reveladas a dimensão espacial (lugar/local) e a natural (organismos vivos). A tendência da EA "conservacionista/recursista" é destacada para promover mudança de comportamento e conscientização, com a finalidade de conservar o ambiente, e a "resolutiva", para tomada de decisão em relação aos problemas ambientais.

A apresentação dos dados nas Tabelas 2 e 3 demonstra maior número de categoria na EEEM quando comparada com a EMEF. Em termos percentuais, as tendências de natureza "naturalista" e a EA "conservacionista/recursista" preponderam nas duas escolas. A principal categoria de meio ambiente destacada na EEEM é a "como sistema", enquanto na EMEF predomina a categoria "como lugar para viver".

\section{Natureza, meio ambiente e Educação Ambiental: (re)construindo conceitos na coletividade}

A segunda etapa (oficina conceitual) teve como objetivo (re)construir os conceitos constatados na primeira etapa (aplicação de questionários) nas EEEM e EEFM. Nessa segunda etapa, foram identificadas três tendências de natureza nos resultados da EEEM, conforme Tabela 4

Na primeira etapa, a concepção de natureza do grupo G1 na EEEM era 8,7\% naturalista, $8,7 \%$ generalista, $8,7 \%$ socioambiental. $\mathrm{Na}$ (re)construção (Tabela 4), o G1 mudou para representação cultural, conforme mostra o conceito: "É a representação cultural que temos de tudo aquilo que é natural", corroborado por Gonçalves (2002). Dessa forma, o grupo considera que 
Lima, A. M.; Oliveira, H. T.

a concepção de natureza é uma representação construída historicamente, mediada pela cultura (GONÇALVES, 2002; CARVALHO, 2004 b; DULLEY, 2004).

Tabela 4. (Re)construção dos conceitos de natureza da coletividade dos professores da EEEM.

\begin{tabular}{lrlll}
\hline Grupos /conceitos & $\%$ & $\begin{array}{c}\text { Concepção na primeira etapa: } \\
\text { aplicação de questionários }\end{array}$ & $\%$ & $\begin{array}{c}\text { Concepção na segunda etapa: } \\
\text { oficina conceitual coletiva }\end{array}$ \\
\hline G1 & 8,7 & Naturalista & 26,1 & Representação cultural \\
& 8,7 & Generalista & & \\
G2 & 8,7 & Socioambiental & 56,5 & Naturalista \\
& 30,4 & Naturalista & & \\
& 17,5 & Utilitarista & & \\
& 4,3 & Sagrada & 17,4 & Socioambiental \\
G3 & 4,3 & Não elucidado & & \\
Total & 8,7 & Generalista & 100 & \\
\hline
\end{tabular}

O G2, antes constituído de 30,4\% naturalista, 17,5\% utilitarista e 4,3\% sagrada e 4,3\% não elucidados, mudou para a concepção naturalista: "E tudo aquilo que tem como característica o fato de ser natural, que envolve todo o meio ambiente sem a intervenção humana".

O G3, que na primeira etapa apresentava a concepção: 8,7\% generalista e 8,7\% naturalista, mudou para socioambiental (TAMAIO, 2002), conforme descreveu durante a oficina: "É tudo aquilo que tem como característica ser natural (ambiente natural) inserindo ser bumano (social) com pouca interferência”. Esse grupo destacou a inserção do ser humano (social) na natureza (mundo natural).

Também nesta segunda etapa (oficina conceitual) foi identificada somente uma tendência de meio ambiente apresentada nos resultados da escola de Ensino Médio (Tabela 5).

Entre os três grupos, a tendência conceitual de meio ambiente do G1 era de 13\% como sistema, 8,7\% lugar para viver e 4,4\% natureza; no G2, 21,6\% apresentaram conceito de meio ambiente como lugar para viver, $13,1 \%$ como biosfera, $13 \%$ como sistema, 4,4\% como recurso e 4,4\% não elucidado; no G3, 13\% apresentaram como sistema e 4,4\% como lugar para viver. $\mathrm{Na}$ (re)construção, todos apontaram para uma mudança considerando a espacialidade e a sua inter-relação com a "multidimensionalidade" (MORIN, 2003; GUIMARÃES, 2005) e a "complexidade" (LEFF, 2003, 2006) ambiental do planeta, conforme destacou o G3, que melhor representa o conceito: "É todo e qualquer espaço ou lugar e suas inter-relações nos meios bióticos, abióticos, como: culturais, históricos, tecnológicos, geográficos, políticos, sociais e econômicos existentes no globo terrestre".

Nesta segunda etapa, foram identificadas duas tendências de EA nos resultados da EEEM (Tabela 6).

Na primeira etapa, a concepção de EA do G1 era: 13\% conservacionista/recursista, 4,4\% humanista, 4,4\% naturalista e 4,4\% cientifica. Durante a segunda técnica, essa concepção mudou para conservacionista/ recursista (SAUVÉ, 2005). 
A (re) construção dos conceitos ...

Tabela 5. (Re)construção dos conceitos de meio ambiente da coletividade dos professores da EEEM.

\begin{tabular}{lrlll}
\hline Grupos /conceitos & $\%$ & $\begin{array}{l}\text { Concepção na primeira técnica: } \\
\text { aplicação de questionários }\end{array}$ & $\%$ & $\begin{array}{c}\text { Concepção na segunda etapa: } \\
\text { oficina conceitual coletiva }\end{array}$ \\
\hline G1 & 13 & Sistema & 26,1 & Multidimensionalidade \\
& 8,7 & Lugar para viver & & \\
4,4 & Natureza & 56,5 & Multidimensionalidade \\
G2 & 21,6 & Lugar para viver & & \\
& 13,1 & Biosfera & & \\
& 13 & Sistema & & \\
& 4,4 & Recurso & 17,4 & Multidimensionalidade \\
& 4,4 & Não elucidado & & \\
G3 & 13 & Sistema & 100 & \\
& 4,4 & Lugar para viver & & \\
Total & 100 & & &
\end{tabular}

Tabela 6. (Re)construção dos conceitos de Educação Ambiental da coletividade dos professores da EEEM.

\begin{tabular}{|c|c|c|c|c|}
\hline Grupos /conceitos & $\%$ & $\begin{array}{l}\text { Concepção na } 1^{\mathrm{a}} \text { etapa: } \\
\text { aplicação de questionários }\end{array}$ & $\%$ & $\begin{array}{l}\text { Concepção na } 2^{\mathrm{a}} \text { etapa: } \\
\text { oficina conceitual coletiva }\end{array}$ \\
\hline G1 & $\begin{array}{r}13 \\
4,4 \\
4,4 \\
4,4\end{array}$ & $\begin{array}{l}\text { Conservacionista/recursista } \\
\text { Humanista } \\
\text { Naturalista } \\
\text { Cientifica }\end{array}$ & 26,1 & Conservacionista/recursista \\
\hline G2 & $\begin{array}{r}43,4 \\
13\end{array}$ & $\begin{array}{l}\text { Conservacionista/recursista } \\
\text { Humanista }\end{array}$ & 56,5 & Crítica social \\
\hline $\begin{array}{l}\text { G3 } \\
\text { Total }\end{array}$ & $\begin{array}{r}17,4 \\
100\end{array}$ & Conservacionista/recursista & $\begin{array}{l}17,4 \\
100\end{array}$ & Crítica social \\
\hline
\end{tabular}

O grupo G2 considerava a tendência de 43,4\% conservacionista/recursista e 13\% humanista. Já no G3, em que 17,4\% eram conservacionistas, mudaram em direção à vertente da crítica social (SAUVÉ, 2005), considerando a cooperação e os valores coletivos. Esses dois grupos demonstraram, em termos conceituais, aspectos relevantes em relação à primeira etapa quando mencionaram a EA como processo permanente de construção individual e coletiva, a formação de cidadania, a sustentabilidade do planeta, conforme destacou o G2: "É um processo de (re)construção individual e coletiva que resultam na formação da cidadania e mudanças de atitudes humanas em relação ao meio ambiente para tornar a vida sustentável no Planeta Terra". Destaca-se, nesses grupos, uma construção pedagógica da EA, como "política" de forma coletiva, por meio da "participação social” (LOUREIRO, 2004; GUIMARÃES, 2006).

$\mathrm{Na}$ sequência, foi identificada, na EMEF, uma tendência para cada concepção (categoria) discutida coletivamente, conforme mostram as Tabelas 7, 8 e 9 .

Na EMEF (Tabela 7), o G4 (único grupo) (re)construiu o conceito de natureza, que antes era assim conceituada: $71,4 \%$ de tendência naturalista, $14,3 \%$ de utilitarista, $14,3 \%$ de meio ambiente (sinônimo); mudou para a concepção naturalista predominante na técnica anterior (TAMAIO, 2002), conforme destacou o grupo 4: "são os elementos naturais que compõem a vida e são essenciais para a sobrevivência". Nesse perspectiva, a natureza é considerada em sua dimensão natural, em consonância com os elementos naturais que garantem a sobrevivência. 
Lima, A. M.; Oliveira, H. T.

Tabela 7. (Re)construção dos conceitos de natureza da coletividade dos professores da EMEF.

\begin{tabular}{lllll}
\hline Grupos /conceitos & $\%$ & $\begin{array}{c}\text { Concepção na primeira etapa: } \\
\text { aplicação de questionários }\end{array}$ & $\%$ & $\begin{array}{c}\text { Concepção na segunda etapa: } \\
\text { oficina conceitual coletiva }\end{array}$ \\
\hline G4 & 71,4 & Naturalista & 100 & Naturalista \\
& 14,3 & Utilitarista & & \\
Total & 14,3 & Meio ambiente & 100 & \\
\hline
\end{tabular}

Tabela 8. (Re)construção dos conceitos de meio ambiente da coletividade dos professores da EMEF.

\begin{tabular}{lrlrl}
\hline Grupos /conceitos & $\%$ & $\begin{array}{c}\text { Concepção na primeira etapa: } \\
\text { aplicação de questionários }\end{array}$ & $\begin{array}{c}\text { Concepção na segunda etapa: } \\
\text { oficina conceitual coletiva }\end{array}$ \\
\hline G4 & 57,1 & Lugar para viver & 100 & Multidimensionalidade \\
& 28,6 & Natureza & & \\
Total & 14,3 & Sistema & 100 & \\
\hline
\end{tabular}

Tabela 9. (Re)construção dos conceitos de Educação Ambiental da coletividade dos professores da EMEF.

\begin{tabular}{lrlrl}
\hline Grupos /conceitos & $\%$ & $\begin{array}{c}\text { Concepção na primeira etapa: } \\
\text { aplicação de questionários }\end{array}$ & $\%$ & $\begin{array}{c}\text { Concepção na segunda etapa: } \\
\text { oficina conceitual coletiva }\end{array}$ \\
\hline G4 & 85,7 & Conservacionista/recursista & 100 & Crítica social e práxica \\
& 14,3 & Resolutiva & 100 & \\
Total & 100 & & &
\end{tabular}

No G4, o conceito de meio ambiente, que era $57,1 \%$ considerado como lugar para viver, $28,6 \%$ como natureza e 14,3\% como sistema, mudou para a dimensão espacial e a interação com a "multidimensionalidade" (Tabela 8), considerando a abordagem relacional (GUIMARÃES, 2006) entre as interconexões e as dimensões do ambiente: “É o que cerca o indivíduo e a interação deste com o aspectos naturais, sociais, culturais, tecnológicos e históricos etc".

A concepção de EAque, na primeira técnica, foi identificada de $85,7 \%$ conservacionista/recursista e 14,3\% resolutiva, mudou, na segunda técnica, para crítica social e práxis (SAUVÉ, 2005). Essa mudança ocorreu devido à característica de a EA ser participativa e reflexiva, e por considerar a inter-relação com o aspecto multidimensional (MORIN, 2003; LEFF, 2003, 2006) do ambiente, conforme descreveu o G4: "É um processo contínuo e participativo que propicia ao cidadão condições de reflexões e revisão de valores e atitudes da família, escola e sociedade considerando a dimensão ecológica, histórica, cultural, política, social e econômica contribuindo com a melhoria da qualidade de vida local e planetária". Essa concepção de EA é considerada como transformadora da realidade social, conforme destaca Loureiro (2004).

$\mathrm{Na}$ EEEM, os professores da área de Ciências Sociais e, sobretudo de Geografia, são os que demonstraram maior visão conceitual nesta segunda etapa. Tanto a concepção de natureza do G1 e do G3 constituem dados relevantes para a ação em EA quando é levada em consideração a dimensão cultural e socioambiental do meio natural. 
Na segunda etapa, a participação coletiva dos professores de diversas áreas de formação acadêmica contribuiu com a (re)construção do conceito de meio ambiente dentro da perspectiva multidimensional. A categoria crítica social apresentada no G2 e G3 constitui um paradigma educativo transformador da realidade socioambiental. Faz-se necessário aprofundar mais o campo teórico-metodológico acerca desta vertente inovadora, para promover ação educativa, visando à sustentabilidade ambiental.

Portanto, repensar a concepção de natureza/meio ambiente é essencial para melhorar a prática da EA, e vice-versa. A práxis refletiva do coletivo de professores e a busca de novos referenciais são relevantes para a ação em EA na escola.

\section{Considerações finais}

O maior número de participantes da pesquisa contribuiu para a diversidade das categorias identificadas entre as duas escolas, lócus desta pesquisa. As diferentes concepções reveladas pelos participantes demonstraram maior complexidade conceitual em relação à concepção de meio ambiente quando comparada com a de natureza. A concepção de meio ambiente identificada como natureza assemelha-se com a de natureza naturalista. Dessa forma, pode-se observar que a natureza é parte integrante do meio ambiente.

Os resultados da concepção de meio ambiente como sistema, detectada nas duas escolas, apontaram, além do aspecto natural, o social. Este último aspecto constitui uma dimensão relevante para que os participantes compreendam os aspectos multidimensionais do ambiente.

A tendência da EA, na segunda etapa (oficina conceitual) nas duas escolas investigadas, apontou para a participação do coletivo na formação da cidadania para a sustentabilidade e melhoria da qualidade de vida planetária. Somente o G3 da EEEM aponta para a tendência de natureza socioambiental, e o G1 considerou o conceito de natureza como construção cultural histórica.

Da primeira para a segunda etapa, a tendência conceitual de EA dos participantes da pesquisa, nas duas escolas (exceto o G1), mudou de uma EA conservacionista/recursista, humanista, naturalista, resolutiva, científica para crítica/transformadora; a concepção de meio ambiente como sistema, lugar para viver, natureza, biosfera e recursos mudou para uma visão espacial; e a relação multidimensional (biológica, social, cultural, histórica, política e outros), no G1, mudou da concepção de natureza naturalista, generalista, socioambiental para representação cultural; no G2, de naturalista, utilitarista, generalista, sagrada para naturalista, e, no G3, de naturalista e generalista para socioambiental.

A pesquisa revelou, na primeira etapa da pesquisa (aplicação dos questionários), ideias antropocêntricas demonstradas na relação dualística homem x ambiente/natureza. Porém, na segunda etapa, durante a realização da oficina para discussão coletiva da concepção de MA, houve uma mudança na (re)construção do conceito baseada no reducionismo biológico/ecológico para a dimensão socioambiental.

O estudo demonstrou que as discussões e trocas de conhecimento de forma participativa, envolvendo professores de diversas áreas de formação acadêmica, possibilitaram um ambiente propício para a aprendizagem de conceitos complexos e polissêmicos, bem como para a (re)construção dos conceitos de natureza, meio ambiente e EA. Este, portanto, pode ser 
Lima, A. M.; Oliveira, H. T.

considerado o primeiro passo para o desenvolvimento de ações de Educação Ambiental escolar. Nessa perspectiva, a escola deve sempre propiciar espaços para outros encontros de diálogos entre os docentes, na construção de propostas de EA para o enfrentamento dos desafios ambientais presentes na região e que se interconectam com todo o planeta Terra.

\section{Referências}

ANDRÉ, M. E. D. A. Etnografia da prática escolar. Campinas: Papirus, 1995.

BOGDAM, R.; BIKLEN, S. Investigação qualitativa em educação. Porto: Porto, 1994.

BRANDÃO, C. R. (Org.). Repensando a pesquisa participante. São Paulo: Brasiliense, 2001.

CARVALHO, I. C. M. Educação Ambiental crítica: nomes e endereçamentos da educação. In: LAYRARGUES, P. P. (Org.). Identidades da Educação Ambiental brasileira. Brasília: MMA, 2004a. p. 25-34.

Educação Ambiental: a formação do sujeito ecológico. São Paulo: Cortez, 2004b.

. Os sentidos de "ambiental": a contribuição da hermenêutica à pedagogia da complexidade. In: LEFF, H. (Coord.). A complexidade ambiental. São Paulo: Cortez, 2003. p. 99-121.

DULLEY, R. D. Noção de natureza, ambiente, meio ambiente, recursos ambientais e recursos naturais. Agricultura em São Paulo, São Paulo, v. 51, n. 2, p. 15-26, 2004.

FERNANDES, E. T.; CUNHA, A. M. O. C.; MARÇAL JUNIOR, O. Educação Ambiental e meio ambiente: concepções de profissionais da educação. In: ENCONTRO DE PESQUISA EM EDUCAÇÃO AMBIENTAL, 2., 2003, São Carlos. Anais... São Carlos: UFSCar, 2003. 1 cd-rom.

FERNANDES NETO, J. Das concepções à prática: Educação Ambiental, meio ambiente e qualidade de vida no ensino fundamental. 2005. 126f. Dissertação (Mestrado em Educação) - Faculdade de Ciências e Letras, Universidade Estadual Paulista, Araraquara, 2005.

GONÇALVES, C. W. P. Os descaminhos do meio ambiente. São Paulo: Contexto, 2002.

GUIMARÃES, M. A dimensão ambiental na educação. 7. ed. Campinas: Papirus, 2005.

Abordagem relacional com forma de ação. In: GUIMARÃES, M. (Org.).

Caminhos da Educação Ambiental: da forma a ação. São Paulo: Papirus, 2006. p. 9-16.

LAYRARGUES, P. P. A crise ambiental e suas implicações na educação. In: QUINTAS, J. S. (Org.). Pensando e praticando a Educação Ambiental na gestão do meio ambiente. 2. ed. Brasília: Ibama, 2002. p. 161-198. 
A (re) construção dos conceitos ...

LEFF, H. (Coord.). A complexidade ambiental. São Paulo: Cortez, 2003.

Epistemologia ambiental. São Paulo: Cortez, 2006.

LOUREIRO, C. F. B. Educação Ambiental transformadora. In: LAYRARGUES, P. P.

(Org.). Identidades da Educação Ambiental brasileira. Brasília: MMA, 2004. p. 65-84.

MORIN, E. Os setes saberes necessários à educação do futuro. 8. ed. São Paulo:

Cortez, 2003.

OLIVEIRA, A. L. Educação Ambiental: concepções e práticas de professores de ciências do Ensino Fundamental. 2006. 139f. Dissertação (Mestrado em Educação para a Ciência e Ensino da Matemática) - Faculdade de Educação, Universidade Estadual de Maringá, Maringá, 2006.

SAUVÉ, L. (Org.). Perspectivas curriculares para la formación de formadores en educación ambiental. In: FORO NACIONAL SOBRE LA INCORPORACIÓN DE LA PERSPECTIVA AMBIENTAL EN LA FORMACIÓN TÉCNICA Y PROFESIONAL, 1. 2003, San Luis Potosi. Memoria... San Luis Potosi: UASLP, 2003. p. 1-20.

. Uma cartografia das correntes de Educação Ambiental. In: SATO, M.;

CARVALHO, I. C. M. (Orgs.). Educação Ambiental: pesquisas e desafios. Porto Alegre: Artmed, 2005. p. 17-44.

SEGURA, D. S. B. Educação Ambiental na escola pública: da curiosidade ingênua à consciência critica. São Paulo: Annablume, Fapesp, 2001.

TAMAIO, I. O professor na construção do conceito de natureza: uma experiência de Educação Ambiental. São Paulo: Annablume, WWF, 2002.

TONISSI, R. M. T. Percepção e caracterização ambientais da área verde da microbacia do córrego da Água Quente (São Carlos, SP) como etapas de um processo de Educação Ambiental. 2005. 281f. Tese (Doutorado em Ciências da Engenharia Ambiental) - Escola de Engenharia, Universidade de São Paulo, São Carlos, 2005.

TOZONI-REIS, M. F. C. Educação Ambiental, natureza, razão e história. Campinas: Autores Associados, 2004.

TUAN, Y.- F. Topofilia: um estudo da percepção, atitudes e valores do meio ambiente. São Paulo: Difel, 1980.

Artigo recebido em setembro de 2010 e aceito em novembro de 2010. 